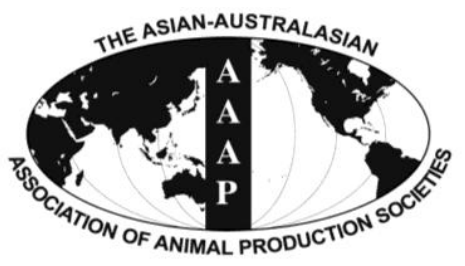

Asian Australas. J. Anim. Sci.

Vol. 26, No. 10 : 1399-1405 October 2013

http://dx.doi.org/10.5713/ajas.2013.13101

www.ajas.info

pISSN 1011-2367 elSSN 1976-5517

\title{
Effects of IFN- $\gamma$ on IL-18 Expression in Pregnant Rats and Pregnancy Outcomes
}

\author{
Li-fang Si, Shou-Yan Zhang ${ }^{1}$, Chun-sheng Gao ${ }^{2}$, Shu-lin Chen ${ }^{3}$, Jin Zhao ${ }^{3}$, and Xiang-chao Cheng* \\ College of Animal Science and Technology, Henan University of Science and Technology, \\ Luoyang, Henan 471003, China
}

\begin{abstract}
The present study focused on establishing the effects of interferon-gamma (IFN- $\gamma$ ) on interleukin-18 (IL-18) expression patterns and pregnancy outcomes in pregnant rats. Pregnant rats at the post-implantation stage were randomized into control, low IFN- $\gamma$ $(\mathrm{L}-\mathrm{IFN}-\gamma)$ and high IFN- $\gamma$ groups $(\mathrm{H}-\mathrm{IFN}-\gamma)$ that received normal saline, $100 \mathrm{IU} / \mathrm{g}$ of IFN- $\gamma$ and $500 \mathrm{IU} / \mathrm{g}$ of IFN- $\gamma$ vaginal muscular injection, respectively. The effects of IFN- $\gamma$ on IL-18 expression and pregnancy outcomes were assessed systematically using several methods, including immunohistochemistry streptavidin-perosidase (SP), image pattern analysis, enzyme-linked immune-sorbent assay (ELISA), whole blood count (WBC) count, microscopy and visual observation. IL-18 was detected in the uteri of all pregnant rats, and mainly distributed in the endometrium, decidual cells, vascular endothelium and myometrium. Immunohistochemistry and image pattern analyses revealed significantly lower IL-18 expression in the H-IFN- $\gamma$ group compared to the L-IFN- $\gamma$ and control groups ( $\mathrm{p}<0.01$ ), indicating that high doses of IFN- $\gamma$ induce downregulation of IL-18 in the uterus of pregnant rats. ELISA results disclosed that IL-18 expression in peripheral blood of the H-IFN- $\gamma$ group was lower than that of the L-IFN- $\gamma$ group $(\mathrm{p}<0.05)$, and significantly reduced compared to the control group ( $\mathrm{p}<0.01)$. Moreover, the number of peripheral leukocytes in the H-IFN- $\gamma$ group was significantly higher than those in the control and L-IFN- $\gamma$ groups $(\mathrm{p}<0.01)$. Morphology analysis showed no evident differences between the L-IFN- $\gamma$ and control groups. However, for the H-IFN- $\gamma$ group, uterine mucosa bleeding, necrosis and excoriation were observed using microscopy. Visual observation revealed marroon, swelling, crassitude and no embryo in the uterus, which are obvious indicators of abortion. These results indicate that IFN- $\gamma$ plays a regulatory role in IL-18 expression in the uterus and peripheral blood of pregnant rats at the postimplantation stage. Moreover, high levels (500 IU/g) of IFN- $\gamma$ influence normal pregnancy at the early stages in rats by downregulating IL-18 expression in the uterus and peripheral blood and increasing the number of peripheral leukocytes, consequently triggering termination of pregnancy. (Key Words: Interleukin-18, Interferon- $\gamma$, Pregnant Rat, Immunohistochemistry, Uterus, Abortion)
\end{abstract}

\section{INTRODUCTION}

Interleukin-18 (IL-18), a recently described member of the IL-1 cytokine superfamily, plays an important regulatory role in inflammation and pathogenic processes of allergic diseases, as well as reproduction and immunoregulation. Earlier, Sakai et al. (2004) showed that the ratio of IL-18 to IL-12 (IL-18/IL-12) is significantly

\footnotetext{
* Corresponding Author: Xiang-chao Cheng. Tel: +86-37960868977, Fax: +86-379-60868977, E-mail: 136707026@qq.com ${ }^{1}$ Department of Cardiology, Luoyang Central Hospital Affiliated to Zhengzhou University, Luoyang 471000, China.

${ }^{2}$ College of Animal Science and Veterinary Medicine, Henan Agricultural University, Zhengzhou, Henan 450002, China.

${ }^{3}$ College of Veterinary Medicine, Northwest A \& F University, Yangling, Shaanxi 712100, China.

Submitted Feb. 12, 2013; Accepted May 29, 2013; Revised Jul. 10, 2013
}

higher in healthy pregnant than non-pregnant women. Elevated IL-18 and decreased IL-12 secretion by peripheral blood mononuclear cells (PBMC) may induce $\mathrm{T}$ helper type 2 (Th2) dominance, which contributes to pregnancy maintenance. Ledee-Bataille et al. (2004) further suggested that the presence of IL-18 in uterine luminal secretions can be used to predict implantation failure. These findings collectively highlight a strong association of IL-18 with embryo implantation and placental development. Interferon- $\gamma($ IFN- $\gamma)$ is a type of Th1 cytokine essential for pregnancy. Earlier research disclosed that high doses of IFN- $\gamma$ induce a low implantation rate and exert an antifertility effect in pregnant rabbits. In the current study, pregnant rats at the post-implantation stage were used as animal models, and the effects of IFN- $\gamma$ on IL-18 expression in the uterus and peripheral blood, as well as leukocytes in peripheral blood investigated using various 
methods, including immunohistochemistry SP, image pattern analysis, ELISA and WBC counting. Moreover, pregnancy outcomes were evaluated with WBC counting, microscopy and visual observation. The causes and mechanisms underlying abortion were demonstrated from an immunological point of view, with the aim of developing novel methods of treating abortion and infertility and determining whether IFN- $\gamma$ can be used as a potential substitute for traditional oral abortifacients. What is more meaningful is to provide some morphological basis for investigating the role of the cytokine network in pregnancy.

\section{MATERIALS AND METHODS}

\section{Experimental animals}

Healthy SD rats weighing 240 to $250 \mathrm{~g}$, purchased from the Henan Laboratory Animal Center LuoYang, China, were fed routinely for 1 week before the experiment. Estrous female rats selected via the vaginal smear method were caged with male rats at a ratio of $1: 1$ overnight. The next morning, female rats were individually assessed, and the day of detection of the vaginal plug or sperm-positive smear was designated first day of pregnancy. Pregnant rats were fed separately.

\section{Sample collection}

Pregnant rats at the post-implantation stage were randomly divided into three groups, control, L-IFN- $\gamma$ and H-IFN- $\gamma$ with 10 animals in each group. Normal saline, 100 and $500 \mathrm{IU} / \mathrm{g}$ of IFN- $\gamma$ were administered vaginal muscular injection, respectively, in keeping with the injection site and dose adopted by Liu et al. (2005). After $48 \mathrm{~h}$, all rats were anesthetized with $10 \%$ chloral hydrate. The thoracic cavity was exposed, followed by aortic cannulation through the left ventricular apex. The blood was replaced with normal saline $\left(37^{\circ} \mathrm{C}\right)$ and subsequently perfusion-fixed with $4 \%$ paraformaldehyde in PBS buffer $\left(\mathrm{pH} 7.4,4^{\circ} \mathrm{C}\right)$. Uteri were removed and fixed with $4 \%$ paraformaldehyde in PBS buffer for $48 \mathrm{~h}$, dehydrated with gradient ethanol, cleared in xylene, embedded in paraffin, and serial sections $(5 \mu \mathrm{m})$. The three sets of sections obtained were used for IL-18 immunohistochemical staining, HE staining and as negative control (for specificity testing), respectively. Changes in the appearance of the uterus were observed visually before removal from the rat body, and micro structure changes observed using microscopy after HE staining. At the same time, blood was drawn from the heart $48 \mathrm{~h}$ after injection and divided into two portions. One fraction was incubated at $37^{\circ} \mathrm{C}$ for $1 \mathrm{~h}$, followed by $4^{\circ} \mathrm{C}$ overnight. The serum was separated immediately and stored in different EP tubes at $-20^{\circ} \mathrm{C}$ used for WBC counting.

\section{Reagents and equipment}

Recombinant human Interferon- $\gamma$ (rhIFN- $\gamma$, Sigma,
Shanghai, China), Rabbit anti-rat IL-18 polyclonal antibody (diluted 1:100, Wuhan Boster Bio-Engineering Co., Ltd, Wuhan, China), Rat IL-18 ELISA Kit (R\&D Systems, Minneapolis, MN, USA), UltraSensitive SP Kit (Maixin.Bio, Fuzhou), Bovine serum albumin (BSA) (CUSABIO, Wuhan, China), Leica CM1900 (Leica Microsystems Nussloch GmbH, German), DG5031 ELISA Microplate Reader (Nanjing Huadong Electronics Group Co., Ltd, Nan Jing, China), Olympus Chc Binocular Microscope (Olympus, Japan), Motic Biomicroscope (Motic China Group Co., Ltd, Xi'an, China), Sartorius AA160 digital balance (Sartorius, Beijing, China), and ST-4A pH meter (Shanghai Precision and Scientific Instrument Co., Ltd, Shanghai, China) were employed for our experiments.

\section{Immunohistochemistry SP and HE staining}

Immunohistochemistry SP method: Sections were deparaffinized, washed with distilled water, and the antigen retrieved by microwaving for $20 \mathrm{~min}$ in citrate buffer. Sections were removed after cooling naturally to room temperature (RT), and rinsed three times with $0.01 \mathrm{~mol} / \mathrm{L}$ PBS (pH 7.4) for 3 min each. Next, sections were incubated with peroxidase suppressing agent (Reagent A) at RT for 10 $\mathrm{min}$, and rinsed three times with $0.01 \mathrm{~mol} / \mathrm{L} \mathrm{PBS}(\mathrm{pH} 7.4)$ for $3 \mathrm{~min}$ each, and subsequently incubated in non-immune animal serum (Reagent B) for $10 \mathrm{~min}$ and rabbit anti-rat IL18 polyclonal antibody (primary antibody) at RT for $1 \mathrm{~h}$, followed by rinsing with $0.01 \mathrm{~mol} / \mathrm{L}$ PBS $(\mathrm{pH} 7.4)$ three times for $3 \mathrm{~min}$ each. Secondary biotin-conjugated antibody (Reagent C) was added and incubated at RT for $10 \mathrm{~min}$, followed by three rinses with $0.01 \mathrm{~mol} / \mathrm{L} \mathrm{PBS}(\mathrm{pH} 7.4)$ for 3 min each. Next, streptavidin-horseradish peroxidase (HRP) conjugate (Reagent D) was added and incubated at RT for $10 \mathrm{~min}$. After rinsing three times with $0.01 \mathrm{~mol} / \mathrm{L} \mathrm{PBS}(\mathrm{pH}$ 7.4) for 3 min each, Diaminobenzidine (DAB) was added (Weight $0.03 \mathrm{~g}$ ), resolved and diluted with $50 \mathrm{~mL}$ of doubledistilled water. The solution was filtered and mixed with 50 $\mathrm{mL}$ of ammonium nickel sulfate-acetic acid buffer, followed by $0.2 \mathrm{~g}$ of glucose, $0.04 \mathrm{~g}$ of ammonium chloride, and $0.001 \mathrm{~g}$ of glucose oxidase to develop color for not more than $30 \mathrm{~min}$. Color development time was controlled by observation using microscopy, and the reaction terminated with distilled water. Solutions were rinsed twice with distilled water and twice with PBS buffer for 15 s each, dehydrated with ethanol, cleared with xylene, and mounted with Canada Balsam. Finally, sections were observed under an optical microscope.

\section{HE staining procedure}

The staining was carried out as follows.

i) Dewax and rehydrate

ii) Mordant in celetine blue for $5 \mathrm{~min}$

iii) Stain in Gull's hematoxylin for $5 \mathrm{~min}$ 
iv) Stain in $2 \%$ safranin for 5 min

v) Rinse in $79 \%$ ehtanol followed by a rinse in $95 \%$ enhanol

vi) Differentiate in absuolute pieric acid/ehtanol for 3 $\min$

vii) Rinse in $95 \%$ ethanol, $70 \%$ entanol, then tap water

viii) Stain in picro indigo carmine for $1 \mathrm{~min}$

ix) Dehydrate, clear and microscope observation

\section{Immunohistochemistry SP results analyse}

In total, 10 high-power fields $(\mathrm{HPF})(\times 400)$ for different sections from the same part of the uterus were selected, and the degree of positive staining quantified using the Image Analysis System (Jiangsu JEDA Science-Technology Development Co., Ltd, Nanjing, China). Average optical density (avA) values and positive area were estimated. Furthermore, relative expression values $\left(\mu^{2}\right)$ were calculated according to the formula below. Data were expressed as $\bar{x} \pm \mathrm{SD}$, and analyzed using one-way ANOVA and T-test (SPSS11.5).

$\mu^{2}=$ multiple of microscope $\times$ avA $\times$ positive area/260,000)

(formula I)

Note: The value of 260,000 refers to pixels.

\section{Determination of IL-18 expression with ELISA}

We added $100 \mu \mathrm{L}$ of $1,000 \mathrm{pg} / \mathrm{mL}, 500 \mathrm{pg} / \mathrm{mL}, 250$ $\mathrm{pg} / \mathrm{mL}, 125 \mathrm{pg} / \mathrm{mL}, 62.5 \mathrm{pg} / \mathrm{mL}, 31.2 \mathrm{pg} / \mathrm{mL}$, and 15.6 $\mathrm{pg} / \mathrm{mL}$ rat IL-18 standard solutions to seven wells in the same row of specific antibody-coated ELISA plates, and $100 \mu \mathrm{L}$ of sample dilution to the eighth well as control. To each well, $100 \mu \mathrm{L}$ of diluted serum was added, the plate sealed and incubated at $37^{\circ} \mathrm{C}$ for $90 \mathrm{~min}$. The liquid was completely removed from all wells by snapping the plate onto absorbent paper several times without washing. Next, $100 \mu \mathrm{L}$ of biotin-conjugated polyclonal antibody specific for IL-18 working solution (Detection Reagent A) was added to each standard well, but not the control well. Plates were incubated at $37^{\circ} \mathrm{C}$ for $60 \mathrm{~min}$, and washed three times with $0.01 \mathrm{~mol} / \mathrm{L}$ PBS buffer for $1 \mathrm{~min}$ each. Avidin-HRP conjugate was added $(100 \mu \mathrm{L})$ to each standard well but not the control well, and the plate sealed and incubated at $37^{\circ} \mathrm{C}$ for $30 \mathrm{~min}$, followed by three washes with $0.01 \mathrm{~mol} / \mathrm{L}$ PBS buffer for 1 to 2 min each. Next, $90 \mu \mathrm{L}$ of TMB substrate solution balanced at $37^{\circ} \mathrm{C}$ for 30 min was added to each well and incubated at $37^{\circ} \mathrm{C}$ with protection from light. When the front three to four standard wells developed visible gradient color, $100 \mu \mathrm{L}$ of TMB Stop Solution was added to each well. After the liquid changed color from blue to yellow, solutions were run on the microplate reader and measurements immediately conducted at $450 \mathrm{~nm}$. The IL-18 concentration in the sample was determined by comparing the OD value to the standard curve.

\section{WBC counting}

To an EP tube containing $20 \mu \mathrm{L}$ of blood, $380 \mu \mathrm{L}$ of $2 \%$ acetic acid was added and allowed to react for $2 \mathrm{~min}$. Subsequently, the appropriate volume was transferred to a hemacytometer and WBCs counted under a microscope.

\section{RESULTS}

\section{Effects of IFN- $\gamma$ on IL-18 expression in uterus of pregnant rats}

In pregnant rats at the post-implantation stage, IL-18 was distributed mainly in the uterine deciduas and myometrium. In control rats, many densely arranged cells staining positive for IL-18 were observed in the uterine deciduas (Figure 1A), along with several positively stained smooth muscle, fibroblast and vascular endothelial cells in the myometrium (Figure 1D). Compared with the control group, less IL-18-positive cells were observed in uterin of the L-IFN- $\gamma$ group, which presented moderate staining (Figure 1B), signifying lower IL-18 expression $(\mathrm{p}<0.05)($ Table 1$)$. Moreover, moderate IL-18 expression in vascular endothelial, smooth muscle and fibroblast cells was observed in the L-IFN- $\gamma$ group. In the H-IFN- $\gamma$ group, the numbers of IL-18-positive cells in both uterine deciduals and myometrium were lower. Notably, IL-18 expression was significantly lower than that in the control $(\mathrm{p}<0.01)$ (Table 1) and L-IFN- $\gamma$ groups $(\mathrm{p}<0.05)$ (Table 1) (Figure $1 \mathrm{C}$ and $1 \mathrm{~F}$ ).

\section{Effect of IFN- $\gamma$ on IL-18 expression in peripheral blood of pregnant rats}

IL-18 expression in peripheral blood of the H-IFN- $\gamma$ group was lower than that of the L-IFN- $\gamma$ group $(p<0.05)$

Table 1. Effect of IFN- $\gamma$ on IL-18 expression in the uterus of pregnant rats

\begin{tabular}{lccc}
\hline Group & $\mathrm{n}$ & $\begin{array}{c}\text { IL-18 expression in uterine } \\
\text { endometrium or deciduas }\left(\mu^{2}\right)\end{array}$ & IL-18 expression in uterine myometrium $\left(\mu^{2}\right)$ \\
\hline Control group & 10 & $47.586 \pm 3.685$ & $25.705 \pm 3.891$ \\
L-IFN- $\gamma$ group & 10 & $39.618 \pm 4.731^{\mathrm{A}}$ & $19.839 \pm 5.094$ \\
H-IFN- $\gamma$ group & 10 & $25.618 \pm 4.031^{\mathrm{aB}}$ & $12.959 \pm 4.049^{\mathrm{aB}}$ \\
\hline
\end{tabular}

\footnotetext{
${ }^{\mathrm{A}}$ Compared with the control group $(\mathrm{p}<0.05) .{ }^{\mathrm{a}}$ Compared with the control group $(\mathrm{p}<0.01) .{ }^{\mathrm{B}}$ Compared with the L-IFN- $\gamma$ group (p<0.05).
} 

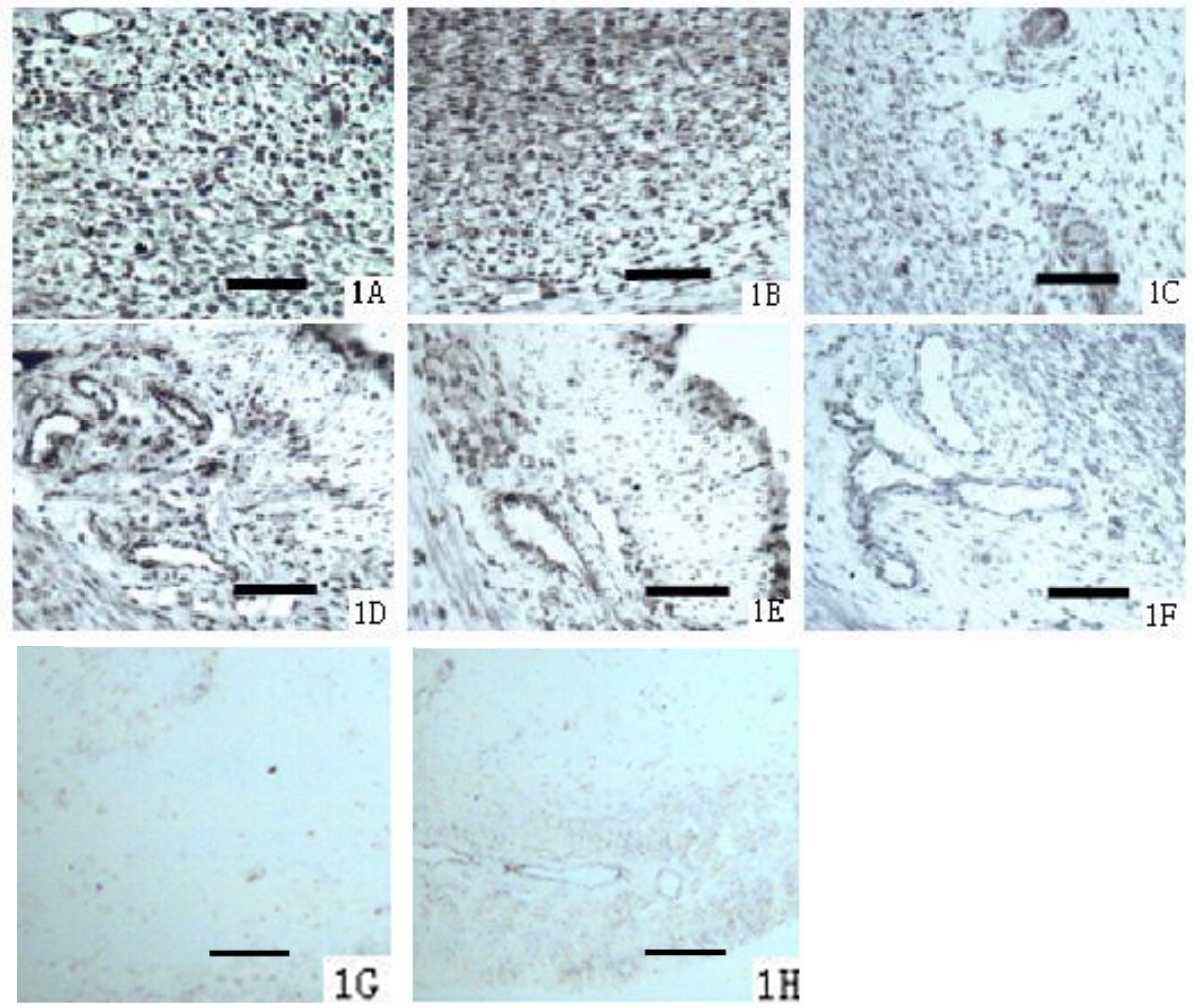

Figure 1. Effect of IFN- $\gamma$ on IL-18 expression in the uterus of pregnant rats (Scale bar $=50 \mu \mathrm{m}$ ). 1A. IL-18 expression in uterine endometrium or deciduas of the control group (400×). 1B. IL-18 expression in uterine endometrium or deciduas of the L-IFN- $\gamma$ group (400×). 1C. IL-18 expression in uterine endometrium or deciduas of the H-IFN- $\gamma$ group (400×). 1D. IL-18 expression in uterine myometrium of the control group $(400 \times)$. 1E. IL-18 expression in uterine myometrium of the L-IFN- $\gamma$ group (400×). 1F. IL-18 expression in uterine myometrium of the H-IFN- $\gamma$ group $(400 \times)$. 1G. Isotype control staining of IL-18 Ab in uterine endometrium or deciduas $(400 \times)$. 1 H. Isotype control staining of IL-18 Ab in uterine myometrium $(400 \times)$.

(Figure 2)and the control group to a more significant extent $(\mathrm{p}<0.01)$ (Figure 2).

\section{Effect of IFN- $\gamma$ on peripheral leukocytes in pregnant} rats

We observed a significantly higher number of peripheral leukocytes in the H-IFN- $\gamma$ group, relative to the control and L-IFN- $\gamma$ groups $(p<0.01)$. Additionally, the number of

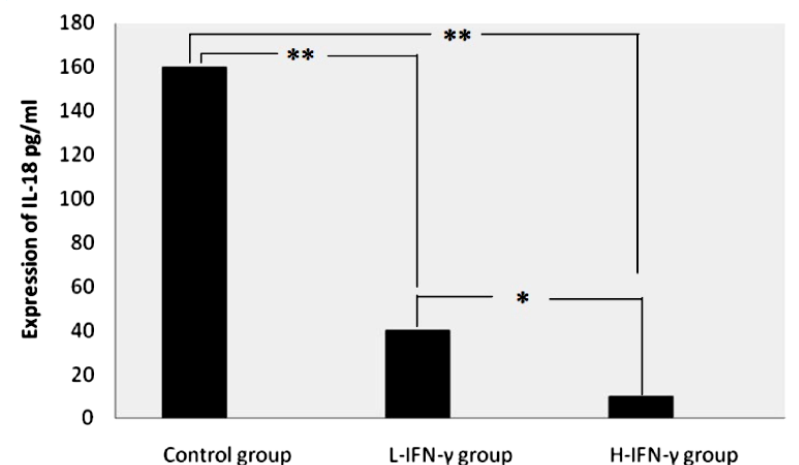

Figure 2. Effect of IFN- $\gamma$ on IL-18 Expression in peripheral blood of pregnant rats. $* * \mathrm{p}<0.05, * * \mathrm{p}<0.01$ peripheral leukocytes in the L-IFN- $\gamma$ group was significantly higher than that of the control group $(\mathrm{p}<0.01)$ (Table 2).

\section{Histological changes in the uterus of pregnant rats}

Changes in the uterus appearance: In the control group, the rat uterus showed normal tissue structure, a pink color and moniliforme, fetation, usually with ten to thirteen embryos, which were large and presented a fresh red color, and surrounded by abundant vessels (Figure 3A). Appearance of the uterus in the L-IFN- $\gamma$ group was similar to that of the control group (Figure 3B). However, for the $\mathrm{H}-\mathrm{IFN}-\gamma$ group, the uterus displayed marroon, swelling and

Table 2. Effect of IFN- $\gamma$ on peripheral leukocytes in pregnant rats

\begin{tabular}{lcc}
\hline Group & $\mathrm{n}$ & $\begin{array}{c}\text { Number of peripheral leukocytes } \\
\left(\text { per each } \mathrm{mm}^{3}\right)\end{array}$ \\
\hline Control group & 10 & $3,881 \pm 38$ \\
L-IFN- $\gamma$ group & 10 & $5,800 \pm 105^{\mathrm{a}}$ \\
H-IFN- $\gamma$ group & 10 & $9,000 \pm 685^{\text {ab }}$ \\
\hline
\end{tabular}

${ }^{a}$ Compared with the control group $(\mathrm{p}<0.01)$.

${ }^{\mathrm{b}}$ Compared with the L-IFN- $\gamma$ group $(\mathrm{p}<0.01)$. 

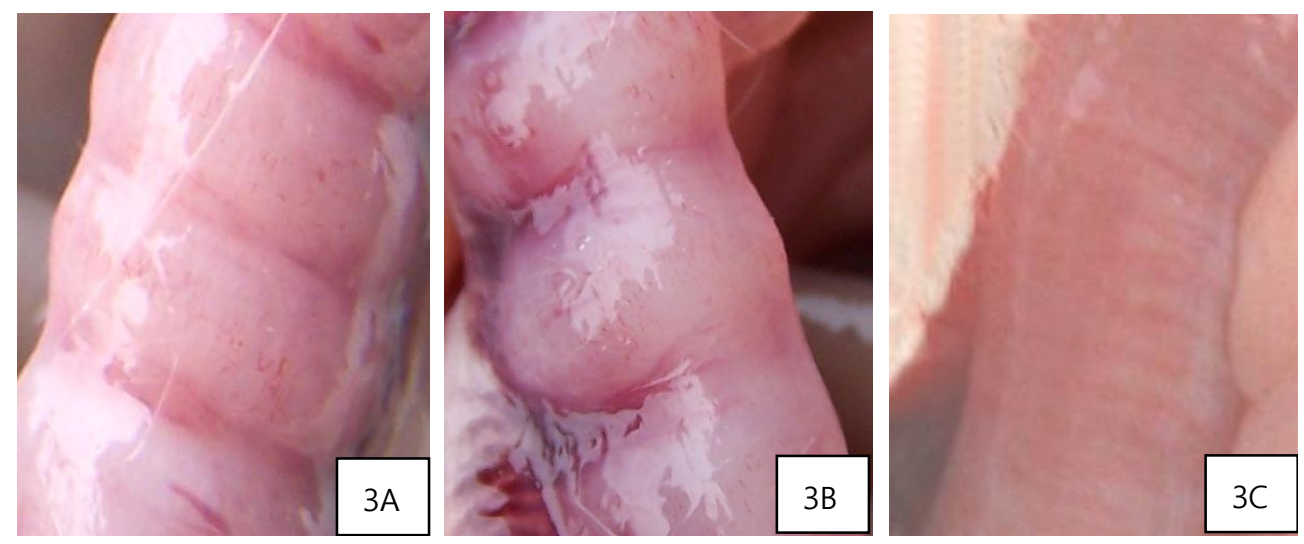

Figure 3. Appearance changes in the uterus. 3A. Uterus of control group rats. 3B. Uterus of L-IFN- $\gamma$ rats. 3C. Uterus of H-IFN- $\gamma$ rats.

crassitude. No embryo was present, but blood clots or reddish-brown vestiges of absorption were observed (Figure $3 \mathrm{C})$.

Histological changes in the uterus: The microstructure of the L-IFN- $\gamma$ group was almost similar to that of the control group, showing integral uterine mucosa and gland structure, localized congestion with no bleeding, necrosis or excoriation, and limited lymphocytes, but no eosinophils (Figure 4A, 4B, 4G, 4H, 4I). However, for the H-IFN- $\gamma$ group, uterine bleeding, necrosis, excoriation infiltrated with neutrophils, deep layer cell breaking, nucleus breakage, inflammatory sites infiltrated with macrophages and plasma cells were observed in the uterine mucosa (Figure 4E). Moreover, phlebectasia, congestion, vascular endothelial proliferation, increased permeability, and vessels surrounded by eosinophils (Figure 4D) were evident. Another notable feature was extensive eosinophil infiltration of uterine smooth muscle and uterine wall
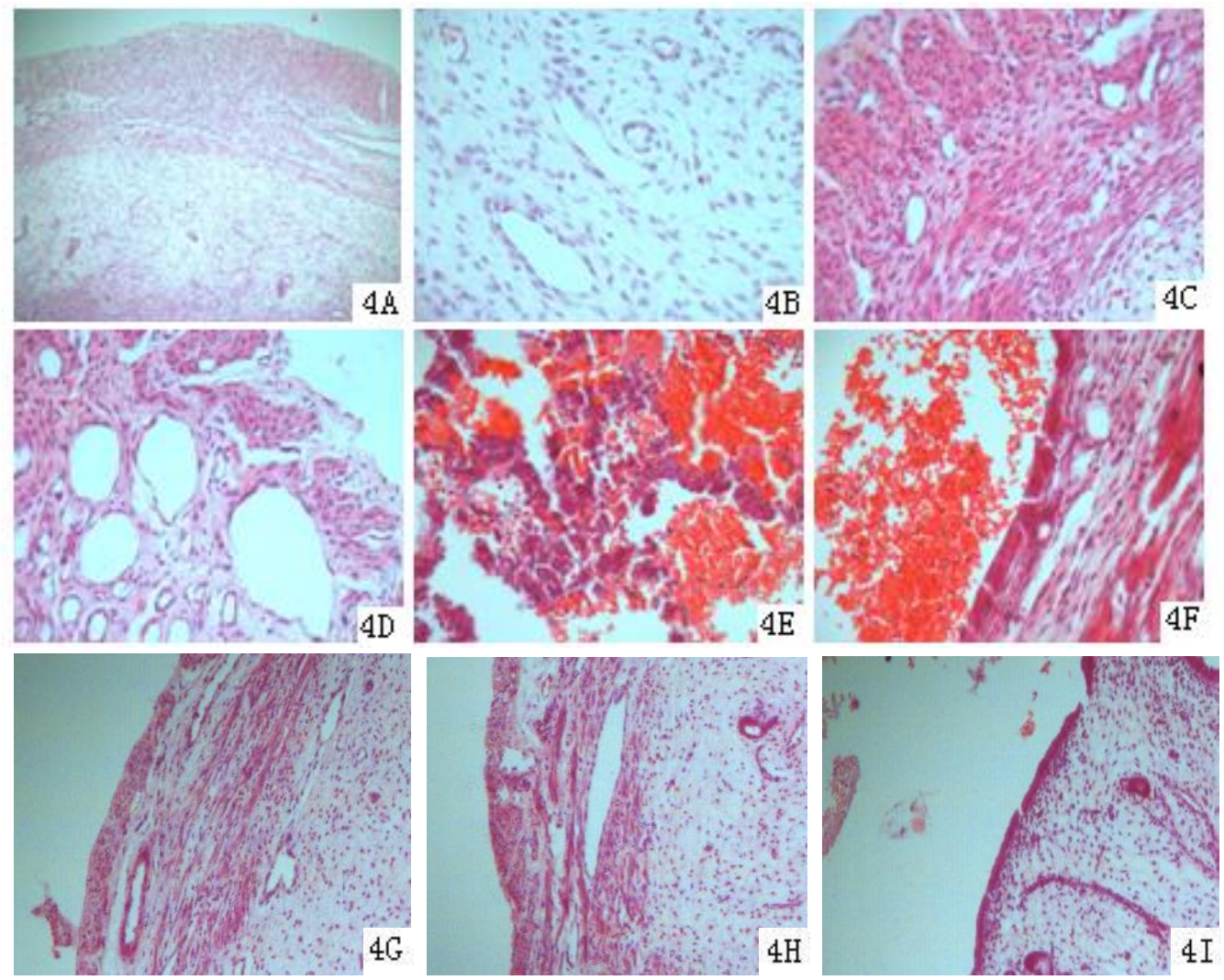

Figure 4. Histological changes in the uterus. 4A. Uterine wall of the control group $(100 \times)$. 4B. Uterine endometrium of the control group (400×). 4C. Uterine myometrium of the H-IFN- $\gamma$ group (400×). 4D. Uterine myometrium vessels of the H-IFN- $\gamma$ group (400×). 4E. Uterine endometrium of the H-IFN- $\gamma$ group $(400 \times)$. 4F. Uterine cavity of the H-IFN- $\gamma$ group $(400 \times)$. 4G. Uterine myometrium of the control group $(400 \times)$. 4H. Uterine myometrium vessels of the control group $(400 \times)$. 4I. Uterine cavity of the control group $(400 \times)$. 
(Figure 4C). Uterine mucosa was infiltrated with several lymphocytes, and the epithelium was thin with numerous eosinophils and red cells (Figure 4F).

\section{DISCUSSION}

Pregnancy involves a complicated immunoregulatory relationship between the maternal and fetal systems, and abortion constitutes a type of immunological rejection reaction with the findings of Gruber et al. (2005). IL-18 with a molecular weight of $18-19 \mathrm{Ku}$ ) was originally identified as a circulating molecule in endotoxin-challenged mice following bacterial priming, cloned from activated macrophages as a IFN- $\gamma$-inducing factor with the findings of Okamura et al. (1995). There is significant evidence that IL-18 plays a vital role in reproduction and immunological regulation with the findings of Shan et al. (2009) and its abnormal expression triggers various diseases. Ostojić et al. (2007), reported that IL-12/IL-18 are involved in uterine NK cell control during uterine vascular development. Polymorphisms in the IL-12/IL-18 genes may thus modify the cytokine balance, resulting in increased susceptibility to recurrent spontaneous abortion (RSA). IL-18 is expressed in immune with the findings of Sugama et al. (2007) and Koibuchi et al. (2006) and endocrine tissues by Wang (2006) and serves as a key immunoregulatory factor in both systems. Additionally, IL-18 has been shown to stimulate NK cells in the pregnant uterus to exert a cytolytic effect. Absence or lack of activation of NK cells by $\mathrm{T}$ cells in the pre- and peri-implantation periods results in abnormal implantation or implantation failure with the findings of Luo et al. (2006). indicating a close relationship between IL-18 expression and pregnancy maintenance. IFN- $\gamma$, one of the factors required for pregnancy is synthesized by activated $\mathrm{T}$ cells and macrophages, and participates in the immunoresponse reaction of organisms with the findings of Goodbourn et al. (2000), Madonna et al. (2010) and Xue et al. (2011). In pregnant uterus, IL-18 is mainly secreted by NK cells and appears essential for normalcy of implantation sites as well as maintenance of decidual cell viability with the findings of Ashkar et al. (1999). However, high IFN- $\gamma$ expression in the deciduas is detrimental to pregnancy. Earlier studies with the findings of Liu et al. (2002) and Thomas et al. (2002) have proposed that IFN- $\gamma$ inhibits progesterone secretion and promotes apoptosis and MHC class II antigen expression in placenta. Data from the current investigation showed that IL-18 expression in the uterus and peripheral blood of pregnant rats is decreased after receiving high doses of IFN- $\gamma$, implying that IFN- $\gamma$ and IL-18 antagonize and restrict each other in the cytokine network, but interact with other cytokines to maintain normal pregnancy. Exogenous IFN- $\gamma$ (500 IU/g) induced abortion in the earlier pregnancy period with a simultaneous decrease in IL-18 levels in the uterus and peripheral blood, suggesting that IL-18 plays an important role in the establishment and maintenance of pregnancy, consistent with the findings of Luo et al. (2006). IL-18 downregulation by IFN- $\gamma$ may be one of the underlying causes of pregnancy failure.

Abortion in pregnant rats was triggered after administration of $500 \mathrm{IU} / \mathrm{g}$ exogenous IFN- $\gamma$, supporting the use of $500 \mathrm{IU} / \mathrm{g}$ as a reference dose for termination of pregnancy. Our findings provide implications for future research on the causes and mechanisms of infertility and treatment methods, and present a novel basis for exploring the inter-regulatory effects of the cytokine network in pregnancy.

Abortion is a type of inflammatory reaction, and IL-18 is an important regulatory factor in inflammation and host defense (Andrea et al., 2003). During inflammation, IL-18 binds to its receptor to induce Th1 and Th2, activates NK cell cytotoxicity, and thereafter, regulates the inflammatory process (Kanno, 2004). In our experiments, IL-18 expression in the uterus and peripheral blood of rats in the $\mathrm{H}-\mathrm{IFN}-\gamma$ group was downregulated, and simultaneously, the number of peripheral leukocytes increased significantly, compared to the L-IFN- $\gamma$ and control groups $(p<0.01)$. Based on the collective results, we propose that since expression of the inflammatory regulator, IL-18, is suppressed during abortion, more leukocytes are generated to inhibit inflammation and compensate for self immunity.

\section{REFERENCES}

Andrea, R., R. D. Wheelerb, and P. D. Collinsa. 2003. Identification of a truncated IL-18Rh mRNA: a putative regulator of IL-18 expressed in rat brain. J. Neuroimmunol. 145:40-45.

Ashkar, A. A. and B. A. Croy. 1999. Interferon contributes to the normalcy of murine pregnancy biology of reproduction. J. Biol. Reprod. 61:493-502.

Cao, Y. Q., D. M. Sun, Y. Z. Chen, and P. D. Zhu. 1999. Studies on the antifertility effect and the mechanism of action of human recombinant interferon-gamma in rabbits. J. Reprod. Med. 8:98-102.

Dosiou, C. and L. C. Giudice. 2005. Natural killer cells in pregnancy and recurrent pregnancy loss: endocrine and immunologic perspectives. J. Endocrine Reviews, 26:44-62.

Goodbourn, S., L. Didcock, and R. E. Randall. 2000. Interferons:cell signalling, immune modulation, antiviral responses and virus countermeasures. J. Gen. Virol. 81:23412364.

Gruber, C. J. and J. C. Huber. 2005. The role of dydrogesterone in recurrent abortion. J. Steroid Biochem. Mol. Biol. 97:426-430.

$\mathrm{Hu}$, C. D. and S. Q. Gui. 2004. Expression and significance of HB-EGF in trophoblast of patients with spontaneous abortion. J. Shanghai Med. J. 27:491-494.

Kanno, T., T. Nagata, S. Yamamoto, H. Okamura, and T. Nishizaki. 
2004. Interleukin-18 stimulates synaptically released glutamate and enhances postsynaptic AMPA receptor responses in the CA1 region of mouse hippocampal slices. Brain Res. 1012:190-193.

Koibuchi, N., M. Fujita, M. Hashimoto, F. S. Dhabhar, and B. Conti. 2006. The adrenal gland is a source of stress-induced circulating IL-18. J. Neuroimmunol. 172:59-65.

Ledee-Bataille, N., F. Olivennes, J. Kadoch, S. Dubanchet, N. Frygdman, G. Chaouat, and R. Frygamn. 2004. Detectable levels of interleukin-18 in uterine luminal secretions at oocyte retrieval predict failure of the embryo transfer. Hum. Reprod. 19:1968-1973.

Liu, M. L., J. P. Peng, Q. H. Sun,Y. Yang, and H. F. Xia. 2005. The expression of TGF- $\beta 1$ in uterus and placenta of pregnant rat and its regulation by IFN- $\gamma$. Progress in Biochemistry and Biophysics 32:413-420.

Liu, Z., Y. Chen, and J. P. Peng. 2002. The effect on MHC class II expression and apoptosis in placenta by IFN- $\gamma$ administration. Contraception 65:177-184.

Luo, Q., W. X. Ning, Y. T. Wu, X. M. Zhu, F. Jin, J. Z. Sheng, and H. F. Huang. 2006. Altered expression of interleukin-18 in the ectopic and eutopic endometrium of women with endometriosis. J. Reprod. Immunol. 72:108-117.

Madonna, S., C. Scarponi, R. Sestito, S. Pallotta, A. Cavani, and C. Albanesi. 2010. The IFN- $\gamma$-dependent suppressor of cytokine signaling 1 promoter activity is positively regulated by IFN regulatory factor-1 and sp1 but repssed by growth factor Independence- $1 \mathrm{~b}$ and Krüppel-Like factor-4, and it is dysregulated in psoriatic keratinocytes. J. Immunol. 185:24672481.

Okamura, H., K. Nagata, T. Komatsu, T. Tanimoto, Y. Nukata, F. Tanabe, K. Akita, K. Torigoe, T. Okura, and S. Fukuda. 1995. A novel costimulatory factor for gamma interferon induction found in the livers of minusc ausesendotoxic shock. Infect. Immun. 63:3966-3972.
Ostojić, S., M. Volk, I. Medica, M. Kapović, H. Meden-Vrtovec, and B. Peterlin. 2007. Polymorphisms in the interleukin-12/18 genes and recurrent spontaneous abortion. Am. J. Reprod. Immunol. 58:403-408

Sakai, M., A. Shiozaki, Y. Sasaki, S. Yoneda, and S. Saito. 2004. The ratio of interleukin (IL)-18 to IL-12 secreted by peripheral blood mononuclear cells is increased in normal pregnant subjects and decreased in pre-eclamptic patients. J. Reprod. Immunol. 61:133-143.

Shan, N. N., X. J. Zhu, J. Peng, P. Qin, X. W. Zhuang, H. C. Wang, and M. Hou. 2009. Interleukin 18 and interleukin 18 binding protein in patients with idiopathic thrombocytopenic Purpura. Br. J. Haematol. 144:755-761.

Shan, N. N., X. J. Zhu, Q. Wang, C. Y. Wang, P. Qin, J. Peng, and M. Hou. 2009. High-dose dexamethasone regulates interlenkin-18 and interleukin-18 binding protein in idiopathic thrombocytopenic purpura. Haematologica 94:1603-1607.

Sugama, S., M. Fujita, M. Hashimoto, and B. Conti. 2007. Stress induced morphological microglial activation in the rodent brain: involvement of interleukin-18. Neuroscience 146:13881399.

Thomas, H. E., R. Darwiche, J. A. Corbett, and T. W. Kay. 2002. Interleukin-1 plus $\gamma$-interferon-induced pancreatic $\beta$-cell dysfunction is mediate by $\beta$-cell nitric oxide production. Diabetes 51:311-316.

Wang, N., S. Sugama, B. Conti, A. Teramoto, and T. Shibasaki. 2006. Interleukin-18 mRNA expression in the rat pituitary gland. J. Neuroimmunol. 173:117-125.

Xue, J. Z., Y. Y. Cui, T. Zhang, S. Q. Liu, H. Q. Duan, Yang Zuo J, G. Hu, and X. Mu. 2011. IFN- $\gamma$ inducing ICAM-1 and IFN$\gamma \mathrm{R} \alpha$ expression in cultured rat intestinal mucosa microvascular endothelial cells. J. Acta Anatomica Sinica 42:622-629. 